\title{
Influence of Attention-Deficit Hyperactivity Disorder (ADHD) on Academic Achievement of Learners in International Primary Schools in Mombasa (Kenya) and Kampala (Uganda): A Comparative Study
}

\author{
Judith Biirah \\ Dr. Alice Anika \\ Prof. Richard Simon Zigler \\ Department of Educational Psychology and Special Needs, \\ Pwani University,Kilifi, Kenya
}

Doi:10.19044/esj.2018.v14n29p199 URL:http://dx.doi.org/10.19044/esj.2018.v14n29p199

\begin{abstract}
Attention deficit hyperactivity disorder (ADHD) is one of the most prevalent disorders among school-going children. The aim of this study was to compare academic achievement of learners with and without ADHD in international primary schools of Mombasa (Kenya) and Kampala (Uganda). A comparative study was conducted among 377 respondents using Attention Deficit Hyperactivity Disorder Scale Questionnaire (SNAP-IV) which assessed the three ADHD subtypes in form of a closed-ended questionnaire. Results revealed that learners with ADHD had low overall academic achievement compared to those without ADHD in Mombasa ( $p<.001)$ and Kampala, ( $<$.001). Boys with ADHD in Mombasa had better grades than girls $(M=168.51, S D=32.50$ vs. $M=160.00, S D=39.07)$ while girls with ADHD in Kampala had better grades than boys $(M=103.50, S D=24.77$ vs. $M=93.45, S D=24.71)$. Learners with ADHD Inattentive subtype were greatly impaired compared to those with ADHD Hyperactive-Impulsive and Combined subtypes in both cities. ADHD significantly predicted academic achievement with higher variability in Kampala (55\%) than Mombasa (10\%). Attention-deficit hyperactivity disorder has a negative impact on academic achievement of learners with the condition. The study recommended integration of ADHD screening in school health services to enable early detection and management of the condition.
\end{abstract}

Keywords: Attention Deficit Hyperactivity Disorder, Academic Achievement, Primary School Children, Mombasa (Kenya), Kampala (Uganda) 


\section{Introduction}

Education is an imperative aspect for national development especially in developing countries including Kenya and Uganda. However, the literacy level in both countries is still low despite efforts directed towards its increase through free primary and secondary education. In spite of these efforts, little is done to identify and eliminate the impediments to learning, especially among children. One of such impediments is attention-deficit hyperactivity disorder (ADHD), which has been identified to affect 3-5\% of primary school children (American Psychiatric Association- APA, 2013).

In an inclusive classroom environment, learners diagnosed with ADHD may find school to be a struggle for a variety of reasons. They may have difficulties with organizational skills, study skills, time management skills, and completion of class work and homework. These learners also may show inability to work within a set of rules causing them problems dealing with teachers and other learners in the school (Collins, 2016). According to Murphy (2014), difficulties associated with ADHD may first become apparent at school due to a mismatch between learners' behavior and classroom expectations.

\section{Review of Problem Situation}

The prevalence of ADHD is globally on the increase and varies from one country to another. Using clinic referred samples; Mpango, Kinyanda, Rukundo, Levin, Gadow, and Patel (2017), Wamithi, Ochieng, Njenga, Akech, and Macharia (2015), and Wamulugwa et al. (2017) established that this condition exists among school going learners in Kenya and Uganda. However, academic achievement of these learners has been reported elsewhere to be more compromised to an extent that they perform below their intellectual ability in math and reading with severe impairment in rising childhood inattention trajectory (Breslau, Miller, Breslau, Bohnert, Lucia, \& Schweitzer, 2009; Pingault et al., 2014).

In a literature review of 30 cross-sectional and four longitudinal studies done by Tosto Momi, Asherson, and Malki (2015), studies pointed at substantial evidence for a negative association between ADHD symptoms and mathematical ability. This association was particularly higher for ADHD inattentive subtype than ADHD hyperactive-impulsive subtype. Holmberg (2012) also found that more learners with ADHD performed poorly in math and English, had been retained in a grade, and did not qualify for upper secondary than controls with a higher impairment in inattentiveness. These findings support the conclusion that among a variety of childhood behavioural problems, attention deficit- a major characteristic of ADHD is the principal predictor of diminished achievement relative to expectations based on a learner's cognitive ability implying that ADHD impairs learners' academic achievement. 
Despite the fact that this disorder exists among school going learners in Kenya and Uganda, no study investigated the effect of this condition on academic achievement of learners in international primary schools. The study at hand thus explored this effect with reference to international primary schools in Mombasa (Kenya) and Kampala (Uganda).

\section{Study Objectives}

1) To compare academic achievement of learners with ADHD and those without ADHD

2) To compare academic achievement between boys and girls with ADHD subtypes

3) To establish academic achievement of learners with different ADHD learners

4) To determine the extent ADHD predicts academic achievement of

\section{Methodology}

A comparative study was conducted to examine academic achievement of learners with ADHD and those without ADHD in international schools of Mombasa (Kenya) and Kampala (Uganda). Research permits were obtained from Pwani University Ethics Remuneration Committee Board and Uganda National Council for Science and Technology, Kampala.

Purposive sampling was used to select both cities as no similar study had been carried out in the study areas. Stratified sampling was used to select schools according to region to ensure proper representativeness. Cluster sampling was used to select learners to avoid omitting learners who might have the ADHD condition. A sample of 377 respondents (236 from Mombasa and 141 from Kampala) participated in the study.

Attention Deficit Hyperactivity Disorder Scale Questionnaire (SNAP IV) developed by Swanson, Nolan, and Pelham (1982) was used to measure ADHD among learners. The instrument has 26 items composed of two areas namely; attention deficit hyperactivity disorder (ADHD) and Oppositional Defiant Disorder (ODD). The study adapted this instrument as only 18 items out of 26 items were used because the last 8 Items measured Oppositional Defiant Disorder (ODD) which was not part of the study. The instrument's Cronbach Alpha reliability from test-retest was reported at .984 and .976 for Mombasa and Kampala respectively; similar to Bussing et al. (2008) from teachers and parents at 0.94 and 0.97 respectively. End of Term Assessment Results (ETAR) involved class teachers recording actual scores attained by individual learners in math, science and English in the previous term from school academic records and scores ranged from 0-100. 


\section{Data Analysis}

Data were analyzed using both descriptive and inferential statistics. An independent samples t-test and One-way ANOVA were used to test the null hypotheses at .05 alpha level. A model was further created to fit the prediction of academic achievement among learners.

\section{Results}

Demographic Characteristics of Respondents

Table 1. Demographic Characteristics of Participants

\begin{tabular}{lll}
\hline Mombasa & Mombasa (\%) & Kampala (\%) \\
\hline Sex & $122(51.7)$ & $62(44.0)$ \\
Male & $114(48.3$ & $79(56.0)$ \\
Female & & \\
\hline Class & $111(47.0)$ & $70(49.6)$ \\
Year Five & $125(53.0)$ & $71(50.4)$ \\
Year Six & & \\
\hline
\end{tabular}

Majority of the participants in the study were girls with $51.2 \%$ compared to boys with $48.8 \%$. Schools in Mombasa had more boys than girls while those in Kampala had more girls than boys. In addition, most of the participants were from year six with $53.0 \%$ in Mombasa and $50.4 \%$ in Kampala.

\section{Comparison of Academic Achievement among Learners with and those without ADHD}

Table 2: Independent Samples t-test on Academic Achievement of Learners with and without ADHD

\begin{tabular}{llll}
\hline Mombasa & $\mathrm{t}$ & $d f$ & Sig (2-tailed) \\
\hline Total & 3.49 & 234 & $\mathbf{. 0 0 1}$ \\
Math & 3.35 & 234 & $\mathbf{. 0 0 1}$ \\
Science & 2.97 & 234 & $\mathbf{. 0 0 3}$ \\
English & 2.92 & 234 & $\mathbf{. 0 0 4}$ \\
\hline Kampala & & & \\
\hline Total & 8.57 & 139 & $\mathbf{. 0 0 0}$ \\
Math & 7.36 & 139 & $\mathbf{. 0 0 0}$ \\
Science & 8.25 & 139 & $\mathbf{. 0 0 0}$ \\
English & 7.55 & 139 & $\mathbf{. 0 0 0}$ \\
\hline
\end{tabular}

An independent samples $t$ test revealed a statistically significant difference in academic achievement between learners with ADHD and those without ADHD in Mombasa: overall achievement $(p<.001)$, math $(p<.001)$, science $(p=.003)$, and English $(p=.004)$. Similarly, there was a statistically significant difference in academic achievement between learners with ADHD and those without ADHD in Kampala: overall achievement $(p<.001)$, math $(p$ $<.001)$, science $(p<.001)$, and English $(p<.001)$. This implied that learners 
with ADHD in both cities were academically impaired than those without the condition in overall achievement and core subjects.

Comparison of academic achievement between boys and girls with ADHD

Table 3: Descriptive Statistics Showing Mean Scores of Learners with ADHD by Sex

\begin{tabular}{|c|c|c|c|c|c|c|}
\hline \multirow[t]{9}{*}{ Mombasa } & Subject & Sex & $\mathrm{N}$ & Mean & SD & Std Error \\
\hline & \multirow[t]{2}{*}{ Total } & Male & 37 & 168.51 & 32.50 & 5.34 \\
\hline & & Female & 18 & 160.00 & 39.07 & 9.21 \\
\hline & \multirow[t]{2}{*}{ Math } & Male & 37 & 54.59 & 15.33 & 2.52 \\
\hline & & Female & 18 & 50.89 & 16.13 & 3.80 \\
\hline & \multirow[t]{2}{*}{ Science } & Male & 37 & 57.22 & 11.35 & 1.87 \\
\hline & & Female & 18 & 53.11 & 16.33 & 3.85 \\
\hline & \multirow[t]{2}{*}{ English } & Male & 37 & 56.70 & 12.93 & 2.13 \\
\hline & & Female & 18 & 56.00 & 14.03 & 3.31 \\
\hline \multirow{8}{*}{ Kampala } & \multirow[t]{2}{*}{ Total } & Male & 11 & 93.45 & 24.71 & 7.45 \\
\hline & & Female & 10 & 103.50 & 24.77 & 8.15 \\
\hline & \multirow[t]{2}{*}{ Math } & Male & 11 & 31.91 & 8.41 & 2.54 \\
\hline & & Female & 10 & 32.30 & 10.03 & 3.17 \\
\hline & \multirow[t]{2}{*}{ Science } & Male & 11 & 27.09 & 10.38 & 3.13 \\
\hline & & Female & 10 & 34.80 & 12.87 & 4.07 \\
\hline & \multirow[t]{2}{*}{ English } & Male & 11 & 34.45 & 11.00 & 3.32 \\
\hline & & Female & 10 & 36.40 & 10.33 & 3.27 \\
\hline
\end{tabular}

Descriptive results in Table 3 revealed that boys with ADHD in schools of Mombasa had higher scores than girls in overall academic achievement $(M$ $=168.51, S D=32.50$ vs. $M=160.00, S D=39.07)$; math $(M=54.59, S D=$ 15.33 vs. $M=50.89, S D=16.13)$; science $(M=57.22, S D=11.35$ vs. $M=$ 53.11, $S D=16.33)$; and English $(M=57.22, S D=11.35$ vs. $M=53.11, S D=$ 16.33). On the other hand, girls with ADHD in schools of Kampala had higher scores than boys in overall academic achievement $(M=103.50, S D=24.77$ vs. $M=93.45, S D=24.71)$; math $(M=32.30, S D=10.03$ vs. $M=31.91, S D=$ $8.41)$; science $(M=34.80, S D=12.87$ vs. $M=27.09, S D=10.38)$; and English $(M=36.40, S D=10.33$ vs. $M=34.45, S D=11.00)$. This implied that girls with ADHD in schools of Mombasa were more academically impaired than boys while boys with ADHD in schools of Kampala were more academically impaired than girls.

\section{Academic Achievement of Learners with Different ADHD Subtypes}

A one way ANOVA revealed a non-statistically significant difference in overall academic achievement among learners with different ADHD subtypes in schools of Mombasa $(p=.511)$. However, learners with ADHD Inattentive subtype were the most affected whereas those with ADHD Hyperactive-Impulsive subtype were the least impaired. Correspondingly, the test revealed a non-statistically significant difference in overall academic achievement among learners with different ADHD subtypes in schools of 
Kampala $(p=.425)$. Even when the test was non-significant, learners with ADHD Inattentive subtype were the most affected while the least affected were those with ADHD Hyperactive-Impulsive subtype. The test further revealed non-statistically significant mean differences in core subjects in Mombasa: math $(p=.324)$, science $(p=.757)$, and English $(p=.260)$; and Kampala: math $(p=.190)$, science $(p=.753)$, and English $(p=.768)$. However, great impairment was observed in those with ADHD Inattentive subtype. This implied that learners with ADHD Inattentive subtype were more academically disadvantaged than those with the other two ADHD subtypes in both samples.

Table 4: One-Way Analysis of Variance on Academic Achievement of Learners with

Different ADHD Subtypes

\begin{tabular}{|c|c|c|c|c|c|c|}
\hline $\begin{array}{c}\text { Mombas } \\
\text { a }\end{array}$ & Source & $d f$ & $S S$ & $M S$ & $F$ & $p$ \\
\hline \multirow[t]{3}{*}{ Total } & Between groups & 2 & 1653.84 & 826.92 & .680 & .511 \\
\hline & Within groups & 52 & 63193.07 & 1215.25 & & \\
\hline & Total & 54 & 64846.91 & & & \\
\hline \multirow[t]{3}{*}{ Math } & Between groups & 2 & 553.80 & 276.90 & 1.52 & .324 \\
\hline & Within groups & 52 & 12499.19 & 240.37 & & \\
\hline & Total & 54 & 13052.98 & & & \\
\hline \multirow[t]{3}{*}{ Science } & Between groups & 2 & 100.03 & 50.01 & .280 & .757 \\
\hline & Within groups & 52 & 9274.08 & 178.35 & & \\
\hline & Total & 54 & 9374.11 & & & \\
\hline \multirow[t]{3}{*}{ English } & Between groups & 2 & 472.44 & 236.22 & 1.38 & .260 \\
\hline & Within groups & 52 & 8893.27 & 171.02 & & \\
\hline & Total & 54 & 9365.71 & & & \\
\hline \multicolumn{7}{|l|}{ Kampala } \\
\hline \multirow[t]{3}{*}{ Total } & Between groups & 2 & 1143.03 & 571.52 & .897 & .425 \\
\hline & Within groups & 18 & 11468.78 & 637.15 & & \\
\hline & Total & 20 & 12611.81 & & & \\
\hline \multirow[t]{3}{*}{ Math } & Between groups & 2 & 272.03 & 136.02 & 1.83 & .190 \\
\hline & Within groups & 18 & 1341.78 & 74.54 & & \\
\hline & Total & 20 & 1613.81 & & & \\
\hline \multirow[t]{3}{*}{ Science } & Between groups & 2 & 89.31 & 44.66 & .288 & .753 \\
\hline & Within groups & 18 & 2788.50 & 154.92 & & \\
\hline & Total & 20 & 2877.81 & & & \\
\hline \multirow[t]{3}{*}{ English } & Between groups & 2 & 63.34 & 31.67 & .268 & .768 \\
\hline & Within groups & 18 & 2127.61 & 118.20 & & \\
\hline & Total & 20 & 2190.95 & & & \\
\hline
\end{tabular}

\section{Predictive Power of ADHD on Academic Achievement of Learners}

The predictive model revealed that ADHD significantly predicted academic achievement of learners in Mombasa: overall achievement $(p<.001$, adjusted $\left.\mathrm{R}^{2}=.101\right)$; math $\left(p<.001\right.$, adjusted $\left.\mathrm{R}^{2}=.090\right)$; science $(p<.001$, adjusted $\left.\mathrm{R}^{2}=.097\right)$; and English $\left(p<.001\right.$, adjusted $\left.\mathrm{R}^{2}=.084\right)$. Similarly, the 
model showed that ADHD significantly predicted academic achievement of learners in Kampala: overall achievement $\left(p<.001\right.$, adjusted $\left.\mathrm{R}^{2}=.552\right)$; math $\left(p<.001\right.$, adjusted $\left.\mathrm{R}^{2}=.454\right)$; science $\left(p<.001\right.$, adjusted $\left.\mathrm{R}^{2}=.492\right)$; and English $\left(p<.001\right.$, adjusted $\left.\mathrm{R}^{2}=.484\right)$. This means that ADHD is a strong negative predictor of academic achievement among learners. Again, ADHD explained more variability in Kampala sample than Mombasa sample implying that this condition put learners in Kampala schools at a more disadvantage than those in Mombasa schools.

Table 5: Significance of ADHD in Prediction of Academic Achievement

\begin{tabular}{|c|c|c|c|c|c|c|}
\hline \multirow{2}{*}{$\begin{array}{l}\text { Model } \\
1\end{array}$} & & \multicolumn{2}{|c|}{ Unstandardized Coefficients } & \multirow{2}{*}{$\begin{array}{l}\text { Standardized Coefficients } \\
\text { Beta }\end{array}$} & \multirow[b]{2}{*}{$\mathrm{t}$} & \multirow[b]{2}{*}{ Sig. } \\
\hline & & B & Std. Error & & & \\
\hline \multirow{5}{*}{$\begin{array}{l}\text { Mombas } \\
\text { a }\end{array}$} & (Constant) & 148.52 & 36.13 & & 4.11 & .000 \\
\hline & Total & -31.14 & 6.91 & -.296 & -4.51 & .000 \\
\hline & Math & -10.79 & 2.86 & -.254 & -3.77 & .000 \\
\hline & Science & -9.89 & 2.73 & -.243 & -3.62 & .000 \\
\hline & English & -10.46 & 2.22 & -.301 & -4.72 & .000 \\
\hline \multirow[t]{5}{*}{ Kampala } & (Constant) & 243.89 & 23.30 & & 10.47 & .000 \\
\hline & Total & -97.88 & 9.25 & -.652 & -10.58 & .000 \\
\hline & Math & -33.16 & 3.84 & -.581 & -8.64 & .000 \\
\hline & Science & -33.32 & 3.39 & -.635 & -9.82 & .000 \\
\hline & English & -31.39 & 3.40 & -.605 & -9.25 & .000 \\
\hline
\end{tabular}

\section{Discussion}

The study investigated the effect of ADHD on academic achievement of learners in international schools of Mombasa and Kampala. The findings were discussed systematically as per objectives. This study makes several inputs to literature using a comparative approach.

Firstly, it provides more empirical evidence on the association between ADHD and academic achievement. For instance this condition impaired academic achievement of learners with ADHD in both samples regardless of improved support services in these schools. Low academic achievement among learners with ADHD has also been highlighted in previous studies (e.g., Afeti \& Nyarko, 2017). However, Zenderski, Sciberras, Mensah and Hiscock (2017) attribute poor achievement among learners with ADHD to low IQ while Bojuweye et al. (2014) challenges this finding by claiming that learners with ADHD have average or even above average IQ. In fact this was beyond the scope of the current study which may thus require another study to be done.

Secondly, the study provides evidence on the relationship between ADHD and academic achievement of boys and girls as girls with ADHD in Mombasa were academically impaired than boys while boys with ADHD in Kampala were academically disadvantaged than girls. Gender differences in academic achievement among learners with ADHD have been reported in 
literature. The finding from Kampala sample corroborate results by Cuffe et al. (2015) who found better academic achievement among females than males with ADHD while results from Mombasa sample are in agreement with Yoshimasu et al. (2011) who found higher impairment among females than males in their longitudinal studies. However, Young, Sabbah, Young, Reiser, and Richardson (2010) found low achievement for both genders. Thus, this gender factor should not be ignored.

Thirdly, although all the three ADHD subtypes impaired academic achievement of learners, greater impairment was recorded in those with ADHD Inattentive subtype in both samples. Low academic achievement among learners with ADHD Inattentive subtype might be explained by the fact that these learners are hardly identified by teachers as impaired and thus no effort is put forward to help them perform at the same level as their peers. This signifies to teachers that they should take an extra effort to intervene and help learners with ADHD Inattentive subtype and stop treating them under "clowns" of disciplined learners. According to van der Kolk et al. (2015), ADHD inattentive symptoms are associated with difficulties in organization skills which lead to decreased self-efficacy and development of depressive symptoms both of which influence the relation between ADHD and academic performance. However, longitudinal studies support our finding as high early childhood inattention was associated with lower teacher-rated academic performance in reading, writing and math while ADHD HyperactiveImpulsive subtype was not a consistent predictor of educational outcomes (Rabiner et al., 2016; Pingault et al., 2014; Salla et al., 2016). On the contrary, Bendiksen et al. (2014) and DuPaul et al. (2014) found higher impairment in ADHD Combined preschool Norwegian and U.S kindergarten through $12^{\text {th }}$ grade learners respectively. This point to the fact that intervention should target at all the three ADHD subtypes as they all put learners with ADHD at an academic disadvantage.

Fourthly, the predictive model showed that ADHD explained more variability among learners in schools of Kampala compared to those in schools of Mombasa. This calls upon the government of Uganda to implement the policy of every school having a professional counselor as this may help enhance academic achievement of these learners. Prediction of academic achievement among learners with ADHD has been reported elsewhere. For instance DuPaul et al. (2014) found that ADHD significantly predicted academic impairment among learners with the condition. Even though the current study revealed higher impairment in Kampala than Mombasa, both cities should pay more attention to this condition as these learners study in an inclusive learning environment with general teachers who may not have special skills to handle them. Nonetheless, controversy has been built on whether it's the ADHD condition or IQ and executive functions or a 
combination of all the three that contribute to low academic achievement among learners with ADHD. Thus, further studies need to investigate this link in the African context.

\section{Conclusion}

In conclusion, ADHD significantly impaired overall academic achievement of learners with the condition in an inclusive learning environment compared to those without the condition; with more impairment in those who had ADHD Inattentive subtype in both cities. The condition also impaired achievement in core subjects (math, science and English). Gender differences in impairment were also observed in the study where girls with ADHD in Mombasa and boys with ADHD in Kampala were greatly academically impaired. A prediction model revealed that ADHD explained more variation in academic achievement among Kampala sample than Mombasa sample. Therefore, these learners should be provided with the necessary support to help enhance their performance.

\section{Recommendations}

The study noticed that learners with ADHD in inclusive learning environments had low academic achievement. Therefore, the governments of both countries should consider classifying ADHD under the category of special needs so as to enhance their academic achievement especially through implementation of Individualized Education Plan (IEP).

The study further established that learners with ADHD Inattentive subtype were severely impaired than those with the other ADHD subtypes. Therefore, it is imperative to integrate the screening of learners for ADHDinto the school health services in order to enable earlydetection and management of the condition.

The study found that girls with ADHD were academically impaired than boys in Mombasa while boys with ADHD were academically disadvantaged than girls in Kampala. Therefore, this gender factor requires another study to be done.

The predictive model showed that ADHD explained more variability among learners in schools of Kampala compared to those in schools of Mombasa. This calls upon the government of Uganda to implement the policy of every school having a professional counselor who can help these learners with ADHD be able to control their behaviours especially amidst academic tasks.

\section{References:}

1. Afeti, K., \& Nyarko, S. H. (2017). Prevalence and effect of attentiondeficit/hyperactivity disorder on school performance among primary 
school pupils in the Hohoe Municipality, Ghana. Annals of General Psychiatry, 16(11), 1-7. doi:10.1186/s12991-017-0135-5

2. American Psychiatric Association (2013). Diagnostic and statistical manual of mental disorders (DSM-V). Arlington, VA: American Psychiatric Publishing.

3. Bendiksen, B., Aase, H., Svensson, E., Friis, S., Myhre, A. M., Reichborn-Kjennerud, T., \& Zeiner, P. (2014). Impairment in young preschool children with symptoms of attention- deficit/hyperactivity disorder and co-occurring oppositional defiant disorder and conduct disorder. Scandinavian Journal of Child and Adolescent Psychiatry and Psychology, 2(3), 95-105.

4. Bojuweye, O., Moletsane, M., Stofile, S., Moolla, N., \& Sylvester, F. (2014). Learners' experience of learning support in selected Western Cape schools. South African Journal of Education, 34(1), 1-15.

5. Breslau, J., Miller, E., Breslau, N., Bohnert, K., Lucia, V., \& Schweitzer, J. (2009). The impact of early behaviour disturbance on academic achievement in high school. Pediatrics, 123(6), 1472-1476. doi:10.1542/peds.2008-1406.

6. Bussing, R., Fernandez, M., Harwood M., Hou, W., Garvan, C. W., Eyberg, S. M., \& Swanson, J. M. (2008). Parent and teacher SNAPIV ratings of attention deficit/hyperactivity disorder symptoms: Psychometric properties and normative ratings from a school district sample. Assessment, 15(3), 317-328. doi:10.1177/1073191107313888.

7. Collins, A. G. (2016). Students with ADHD: Can they find success in the classroom? Education Masters. Paper 331.

8. Cuffe, S. P., Visser, S. N., Holbrook, J. R., Danielson, M. L., Geryk, L. L., Wolraich, M. L., \& McKeown, R. E. (2015). ADHD and psychiatric comorbidity: Functional outcomes in a school-based sample of children. Journal of Attention Disorders, 1-10. doi:10.1177/1087054715613437.

9. DuPaul, G. J., Reid, R., Anastopoulos, A. D., \& Power, T. J. (2014). Assessing ADHD symptomatic behaviors and functional impairment in school settings: Impact of student and teacher characteristics. School Psychology Quarterly, 29(4), 409-421. doi:10.1037/spq0000095

10. Holmberg, K. (2012). Adolescent academic outcome of childhood attention-deficit/hyperactivity disorder- a population-based study. Contemporary Trends in ADHD Research, 88-106. doi:10.5772/31022. 280-285.

11. Mpango, R. S., Kinyanda, E., Rukundo, G. Z., Levin, J., Gadow, K. D., \& Patel, V. (2017). Prevalence and correlates for ADHD and 
relation with social and academic functioning among children and adolescents with HIV/AIDS in Uganda. BioMed Central Psychiatry, 17(336) 1-8. doi:10.1186/s12888-017-1488-7

12. Murphy, S. (2014). Inclusive strategies for students with characteristics of ADHD. Young Children, 69(3), 66 -71.

13. Pingault, J-B., Côté, S. M., Vitaro, F., Falissard, B., Genolini, C., \& Tremblay, R. E. (2014). The developmental course of childhood inattention symptoms uniquely predicts educational attainment: A 16year longitudinal study. Psychiatry Research, 19(3), 707-709. doi:10.1016/j.psychres.2014.06.022

14. Rabiner, D. L., Carrig, M. M., \& Dodge, K. A. (2016). Attention problems and academic achievement: Do persistent and earlieremerging problems have more adverse long-term effects? Journal of Attention Disorders, 20(11), 946-957. doi:10.1177/1087054713507974

15. Salla, J., Michel, G., Pingault, J. B., Lacourse, E., Panquin, S., Galera, C., ... \& Cote, S. M. (2016). Childhood trajectories of inattentionhyperactivity and academic achievement at 12 years. European Journal of Child and Adolescent Psychiatry, 1-12. doi: 10.1007/s00787-016-0843-4

16. Swanson, J. M., Nolan, W., \& Pelham, W. E. (1982). SNAP rating scale. Ipswich, MA: Educational Resources in Education.

17. Tosto, M. G., Momi, S. K., Asherson, P., \& Malki, K. (2015). A systematic review of attention deficit hyperactivity disorder (ADHD) and mathematical ability: Current findings and future implications. BMC Medicine, 13, 204-217. doi:10.1186/s12916-015-0414-4

18. van der Kolk, A., van Agthoven, M., Buitelaar, J. K., \& Hakkaart-van Roijen, L. (2015). A Systematic review of literatures on factors associated with educational and academic performance in attention deficit hyperactivitydisorder. Creative Education, 6, 164-180. doi:10.4236/ce.2015.62015

19. Wamithi, S., Ochieng, R., Njenga, F., Akech, S., \& Macharia, W. M. (2015). Cross-sectional survey on prevalence of attention deficit hyperactivity disorder symptoms at a tertiary care health facility in Nairobi. Child and Adolescent Psychiatry and Mental Health, 9(1), 17.doi:10.1186/s13034-015-0033-z.

20. Wamulugwa, J., Kakooza, A., Kitaka, S. B., Nalugya, J., Kaddumukasa, M., Moore, S., ... \& Katabira, E. (2017). Prevalence and associated factors of attention deficit hyperactivity disorder (ADHD) among Ugandan children: A cross-sectional study. Child and Adolescent Psychiatry and Mental Health, 11(18), 1-7. doi:10.1186/s13034-017-0155-6 
21. Young, E. L., Sabbah, H. Y., Young, B. J., Reiser, M. L., \& Richardson, M. J. (2010). Gender differences and similarities in a screening process for emotional and behavioral risks in secondary schools. Journal of Emotional and Behavioral Disorders, 18(4), 225235. doi: $10.1177 / 1063426609338858$

22. Yoshimasu, K., Barbaresi, W. J., Colligan, R. C., Killian, J. M., Voigt, R. G., Weaver, A. L., \& Katusic, S. K. (2011). Written language disorder among children with and without ADHD in a populationbased birth cohort. Pediatrics, 128(3), e605-e612.

23. Zenderski, N., Sciberras, M., Mensah, F., \& Hiscock, H. (2017). Academic achievement and risk factors for adolescents with ADHD in middle school and early high school. Journal of Developmental and Behavioral Pediatrics, $38(6)$, 358-368. doi:10.1097/DBP.0000000000000460. 